\title{
An evaluation of English e-book 'Think Globally Act Locally' for the ninth graders
}

\author{
Sri Meiweni Basra \\ srimeiweni.basra@yahoo.com \\ Universitas Negeri Padang \\ Jl. Prof. Dr. Hamka Air Tawar Padang, Indonesia \\ Pupung Purnawarman \\ purnawarman@upi.edu \\ Universitas Pendidikan Indonesia \\ Jl. Dr. Setiabudhi Nomor 299 Bandung, Indonesia
}

Received: July 27, 2017;

Accepted: January 24, 2018;

Published: March 2, 2018

\begin{abstract}
This research investigated whether the 2013 curriculum English electronic book (e-book) 'Think Globally Act Locally' was categorized as a good quality e-book and how the e-book represented the criteria of a good quality e-book. By using the principle of qualitative research, a criteria checklist was used as the research instrument. The result showed that the e-book met $59 \%$ out of 66 criteria of a good quality e-book. The strengths of the e-book were in terms of the relation between the content provided and students' real-life situation, amount of exposure of speaking skills and grammar, and its appealing physical appearance. However, drawbacks such as failures to promote target culture learning, to expose language skills and sub-skills equally and to accommodate supplementary materials and digital features were found. The findings of the research showed that improvements toward the e-book should be made. Hopefully, this research provides insights for e-book writers to create more improved e-books by meeting the criteria of a good e-book and for English teachers to be effective in using learning materials.
\end{abstract}

Keywords: coursebook evaluation, digital features, English e-book, e-book criteria 
How to cite this paper: Basra, S. M., \& Purnawarman, P. (2018). An evaluation of English e-book 'Think Globally Act Locally' for the ninth graders. Journal on English as a Foreign Language, 8(1), 57-74 (doi: 10.23971/jefl.v8i1.647)

DOI: http://dx.doi.org/10.23971/jefl.v8i1.647

Coursebooks have been one of the primary materials that classrooms normally use. In Indonesia, especially, many coursebook publishing companies grow rapidly in response to classroom needs of the use of coursebooks in the teaching and learning process. Even, Indonesian Education Ministry of Education and Culture has also taken an action to publish coursebooks for all subjects and all levels. This reality depicts that coursebooks are considered to be an important matter to be provided in classrooms. As one of the school subjects, English subject is also taught using coursebooks.

There are a number of advantages of using coursebook in English classroom which have been defined by experts over the years. For a starter, Ansary and Babaii (2002) state that coursebooks help to control the teaching and learning process in classrooms. Therefore, a careful selection of coursebooks usually defines good results and an inappropriate selection usually causes regrets. Harmer (2007) further explains that with good coursebooks, most of the needs in the classroom (the needs of students as well as the program) are reflected in the coursebook making it easy for both teachers and students to achieve learning objectives. Good English coursebooks provide an appropriate language, contents and sequences of the material which suit the expectation of the students and the program. Thus, coursebooks are regarded as convenient ways for teachers to take learning materials from. Many other experts like Robinson, Richards, Nunan and Cunningsworth as cited in Zohrabi (2011) also point out several advantages of using coursebooks. For example, coursebooks help both teachers and students in the process of teaching and learning in the classroom by providing framework and syllabus of a program, promoting learners autonomy, providing a variety of learning resources, and serving as a plan in teaching which offers effective inputs as guidance to train teachers.

However, there are also potential problems caused by using coursebooks. Problems like cultural appropriateness which is sometimes neglected and the ignorant of coursebook writers about the winds of change of new methodology, research, and classroom feedback are possible to appear if an inappropriate coursebook gets selected and used. Harmer (2007) also argues that the trust the teachers and learners have on a coursebook will get them locked in the book and see the coursebook as an instruction for action rather 
than a proposal for action. By blatantly adopting materials presented in a coursebook without having to make any changes, this attitude gives negative results on teaching and learning process such as causing the learning to become monotonous and boring. Monotonous teaching and learning process may demotivate students to get involved in classroom activities. Chou (2010) also expresses concerns about the same thing as repetitiveness in a coursebook such as answering to questions after reading texts or doing multiple choice every at the end of the units will lead students to find the learning process uninteresting.

The reality that not all coursebooks match the needs of students and programs urges teachers and those dealing with the writing and designing of coursebooks to do an evaluation. Hutchinson and Waters as cited in Sarem, Hamidi and Mahmoudie (2013) acknowledge in a nutshell that coursebook evaluation is a process involving a procedure to find out whether the coursebook and criteria expected by a program or teacher are aligned. Therefore, to reach for a decision of getting a suitable coursebook for teaching and learning process, a careful and comprehensive coursebook evaluation is needed.

For decades, scholars have developed lists of criteria for coursebook evaluation. Mukundan, Hajimohammadi, and Nimehcisalem (2011) mention that the evaluative criteria are uncertain or may not be similar between one evaluator and the other because they should take into account the learningteaching context and the specific needs of learners and the teacher. However, based on a number of lists of evaluation criteria developed by scholars in many parts of the world, many of them are found to have similarities._Some similarities of primary criteria which are considered important to be evaluated are the content of the coursebook, layout and considerations which are related to the practicality. Harmer (2007), for instance, has ten categories of criteria for coursebook evaluation. They are price and availability, add-ons and extras, layout and design, instructions, methodology, syllabus, language skills, topics, cultural appropriacy, and teacher's guide. Meanwhile, Mukundan et al. (2011) divide 27 criteria for textbook evaluation into two major categories; general attributes and learning-teaching content. General attributes include lists of criteria related to the relation of the book to syllabus and curriculum, methodology, suitability to learners, physical and utilitarian attributes, and supplementary materials. Learning-teaching content includes criteria related to how four language skills (listening, speaking, reading and writing), three subskills (pronunciation, grammar and vocabulary), and exercises provided are dealt in the coursebooks.

Due to a high demand for coursebooks, the number of coursebooks keeps evolving over the years. Publishing companies keep producing 
coursebooks regularly by offering something new and different (such as new approach, curriculum and the likes) to attract coursebook consumers. They even have started to produce coursebooks in different forms such as by making printed coursebooks digitalized (e-book). This action is taken to catch up with modernized era and give options for people regarding the simplicity of using coursebooks.

In Indonesia, although printed coursebooks are still favored, the publishing of electronic books has also started to grow. In fact, the Ministry of Education and Culture has started to publish electronic coursebooks in these recent years. There are a number of electronic coursebooks provided by the Ministry of Education and Culture, some of which are electronic coursebooks intended for the implementation of the 2013 curriculum. Being on hold, there is a possibility that the 2013 curriculum will be back on. In response to that, several 2013 curriculum coursebooks have been revised, reevaluated and republished in second edition formats, including English coursebooks. This evaluation and revision are aimed at providing teachers and students better and more suitable teaching and learning materials. However, there are 2013 curriculum English coursebooks which have not yet been reevaluated.

There has been a number of research carried out focusing on the evaluation of the 2013 curriculum English coursebooks since their publication. Arba'ati (2015) investigated whether the themes provided in the 2013 curriculum English coursebook for grade eight aligns with basic competence of English learning defined in the 2013 curriculum. By employing a descriptive qualitative research, she found that only $69.2 \%$ of units in the coursebook aligns with basic competence of the 2013 curriculum. The research shows that the coursebook has not yet been totally aligned with basic competence defined by the curriculum even if the coursebook is published by the Ministry of Education and Culture. Meanwhile, Nimasari (2015) discussed coursebook evaluation by highlighting different angles. Nimasari (2015) conducted a coursebook evaluation to the 2013 Curriculum English coursebook intended for grade ten. The objectives of the research were to find out how the coursebook accomplishes pedagogical aspects and students' responses toward the textbook. After the evaluation and analysis, it is found that the coursebook has both strengths and weaknesses in pedagogical aspects. It has strengths in terms of the methodology, presentation, design and learners' factors. However the weaknesses lie in the matter of content coverage and material completeness. Next for students' responses, it is found that the coursebook is quite beneficial and challenging. The third research, Sholihah (2016) investigated how the 2013 curriculum English coursebook for eleventh graders meet the criteria of a good coursebook. The finding shows that the coursebook analyzed is categorized to 
be a very good coursebook because the coursebook provided materials based on the rules defined in the curriculum. Further, a research concerning the realization of e-books in EFL teaching and learning process was conducted by Priajana and Baehaqi (2012). They found that due to teachers' limitation in using technology, they were not yet aware that e-books had benefits for EFL teaching and learning process. Therefore, most of the teachers relied heavily on printed coursebooks.

Referring to the problems of coursebook elaborated earlier and all research on English coursebook evaluation, especially English coursebook intended for the implementation of the 2013 curriculum which are published by Indonesian Ministry of Education and Culture, this research fills the gap by focusing on the evaluation of the 2013 curriculum English electronic coursebook for ninth graders. This is also carried out as there are still very few studies conducted on the area of evaluating the 2013 curriculum English coursebook in the form of electronic book. Therefore, there are two objectives of the research. The first one is to find out whether the 2013 curriculum English electronic book 'Think Globally Act Locally' for the ninth graders meet the criteria of a good quality electronic book (e-book) and the second one is to investigate the extent to which the aforementioned e-book represent a good quality e-book based on e-book evaluation criteria.

\section{METHOD}

Since this research was aimed at finding out whether the 2013 curriculum English electronic book 'Think Globally Act Locally' for the ninth graders met the criteria of a good quality electronic book (e-book) and investigating how the aforementioned e-book represented a good quality ebook based on e-book evaluation criteria, this study was categorized as a qualitative research. Cohen (2007) states that making sense of the data obtained directly from participants is the aim of a qualitative research. Further, Creswell (2011) mentions several characteristics of qualitative research. Qualitative research requires an exploration of a problem and provides detailed information about a phenomenon. Referring to the characteristics, this study was categorized as a qualitative research since it gathers information and making sense of a phenomenon through an evaluation of a particular document.

The main subject of this study was the 2013 curriculum English e-book 'Think Globally Act Locally' for the ninth graders. The e-book was published by the Indonesian Ministry of Education and Culture in 2015. Consisting of 273 pages, this e-book is divided into fourteen units which consist of the whole year lesson.

Journal on English as a Foreign Language, 8(1), 57-74

Copyright (C) 2018 by JEFL, p-ISSN 2088-1657; e-ISSN 2502-6615 
The aforementioned e-book was selected under the consideration that, unlike other e-books for other levels which have been revised once and have been republished in their second edition, this e-book has not been revised yet since its first publication.

The e-book 'Think Globally Act Locally' was evaluated using an eclectic checklist. The checklist was a blend of two separate checklists (Demir \& Ertas, 2014; Marczak, 2013). As the subject to be evaluated was a coursebook with digital features, the criteria included in the checklist did not only serve to evaluate the layout and the completeness of the content and language skills of the coursebook, but also its digital features.

The checklist employed in this study consisted of 66 criteria (in the form of questions) in total which are divided into six major categories. The categories are subjects and contents, sub-skills and skills, layout and physical make-up, practical consideration, functionalities and device and format. The first category (subjects and contents) consisted of the criteria related to how contents are presented in the e-book in relation to cultural appropriateness, the variation of topics, local and target culture learning and the like. The second category consisted of criteria to evaluate how the four language skills (reading, listening, speaking and writing) and three sub-skills (vocabulary, grammar and pronunciation) are dealt in the e-book. The third category was layout and physical make-up. The attractiveness of the layout of the coursebook including the pictures, diagrams and tables and also the printing quality were included in the criteria under this category. Criteria of e-book layout in relation to digital features were also included in the third category. The fourth category was related to practical considerations of the book. The criteria included figuring out whether the e-book was accessible, affordable, up-to-date, related to curriculum goals, provided supplementary materials and the like. The fifth category was related to investigating the functionalities of the e-book. It tried to investigate whether the e-book had hyperlinked, multimedia, and tools to do bookmarking and annotation.

The first thing to do in the procedure of collecting the data was gaining access to a website owned by the Ministry of Education and Culture. The website provides e-book for all levels and subjects by taking no charge for downloading the e-book. With no registration needed, the e-book was downloaded in short period of time.

After the data was collected, the analysis began. A brief overview of the e-book was worth doing to get familiar with the e-book layout and content in general. Then, the e-book was evaluated in terms of criteria listed in the checklist (the instrument). The checklist required the rating of each of the criteria in a 'yes' or 'no' value. If the e-book matched a criteria then a tick is put 
in 'yes' column. Meanwhile, if the e-book did not match a criteria then a tick was put in 'no' column. After all those criteria were investigated, the number of the criteria in each column was counted and turned into a percentage. The result then was interpreted into one of the following conditions; if the e-book represented more than $80 \%$ of criteria, it was considered as a good quality ebook; if the e-book represented the listed criteria in the range of $60 \%$ to $80 \%$, it meant the e-book could be used but it needed adaptation; if the e-book represented less than $60 \%$ of criteria, it meant that the e-book was not suitable to be used. The finding of each major category of criteria was elaborated descriptively in detail and also supported by relevant theories in the next section.

\section{FINDINGS}

\section{English E-book 'Think Globally Act Locally' for the Ninth Graders Based on the Criteria of a Good Quality E-book}

The finding of this first research objective is presented on Table 1 (a checklist) and followed by the result which is presented in percentage.

Table 1. The Result of E-book 'Think Globally Act Locally' Evaluation

\begin{tabular}{|c|c|c|}
\hline Criteria & Yes & No \\
\hline \multicolumn{3}{|l|}{ Subjects and contents } \\
\hline $\begin{array}{l}\text { Does content serve as a window into learning about the target language } \\
\text { culture? }\end{array}$ & & \\
\hline Are the subject and content of the e-book interesting? & $\checkmark$ & \\
\hline Is the content of the e-book challenging enough to foster new learnings? & $\checkmark$ & \\
\hline Is there sufficient variety in the subject and content of the e-book? & $\checkmark$ & \\
\hline Is the thematic content culturally appropriate? & $\checkmark$ & \\
\hline $\begin{array}{l}\text { Are the topics and texts free from any kind of discrimination (gender, } \\
\text { race, etc)? }\end{array}$ & $\checkmark$ & \\
\hline $\begin{array}{l}\text { Is there a relationship between the content of the e-book and real-life } \\
\text { situations (society)? }\end{array}$ & $\checkmark$ & \\
\hline $\begin{array}{l}\text { Do the topics and texts in the e-book include elements from both local } \\
\text { and target culture? }\end{array}$ & & $\checkmark$ \\
\hline \multicolumn{3}{|l|}{ Sub-skills and skills } \\
\hline \multicolumn{3}{|l|}{ Reading } \\
\hline $\begin{array}{l}\text { Are there adequate and appropriate exercises and tasks for improving } \\
\text { reading comprehension? }\end{array}$ & & $\checkmark$ \\
\hline $\begin{array}{l}\text { Is there a wide range of different reading texts with different subject } \\
\text { content? }\end{array}$ & & $\checkmark$ \\
\hline Are the reading selections authentic pieces of language? & $\checkmark$ & \\
\hline \multicolumn{3}{|l|}{ Listening } \\
\hline Does the e-book have appropriate listening tasks with well-defined & $\checkmark$ & \\
\hline
\end{tabular}


goals?

Is the listening material well recorded, as authentic as possible?

Is the listening material accompanied by background information,

questions and activities which help comprehension?

Speaking

Does the e-book include speech situations relevant to students' background?

Are the activities developed to initiate meaningful communication?

Does the e-book include adequate individual and group speaking activities?

Writing

Are models provided for different genres?

Do the tasks have achievable learning goals and take into consideration learners capabilities?

Is practice provided in controlled and guided composition in the early stage?

Vocabulary

Does the vocabulary load (i.e. the number of new words introduced in every lesson) seem to be reasonable for the students of that level?

Is there a good distribution (simple to complex) of vocabulary load across units and the whole book?

Do the vocabulary exercises promote internalization of previously and newly introduced items?

Is the new vocabulary integrated in varying contexts and situations?

Grammar

Are the grammar points presented with brief and easy examples and explanations?

Is the primary function of new structures for interaction and communication?

Do the structures gradually increase in complexity to suit the growing reading ability of students?

Are the new structures presented systematically and in a meaningful context?

Are the grammar points recycled in the following units?

Pronunciation

Is there sufficient work on recognition and production of stress patterns, intonation and individual sounds?

Are the pronunciation points repeated and reinforced in subsequent lessons?

Does the e-book cover other sub-skills like note-taking, skimming, scanning, inferring meaning, listening for gist, etc.?

Layout and Physical Make-up

Is the color of layout in high quality? 
Does the e-book look interesting and fun?

Does the e-book include a detailed overview of the functions and structures that will be taught in each unit?

Does the e-book reflect learners' preferences in terms of layout, design, and organization?

Does the e-book contain enough pictures, diagrams, tables etc. helping students understand the printed text?

Are the illustrations informative and functional?

Do the size and weight of the e-book seem convenient for students to handle?

Does the e-book contain an informative cover, featuring the name of author, the title, the date of publication and the publisher's details?

Does it have a clearly defined or user-friendly layout (section, units)?

Does the interface feature other navigation clues which makes particular elements of content accessible?

Are colour schemes used to aid searching?

Are the fonts visible?

Practical Considerations

Is the e-book up-to-date (e.g. published within the past 10 years)?

Is the e-book easily accessible?

Is the e-book affordable?

Does the e-book have supplementary materials (tapes, visuals etc.)?

Does the e-book have supporting online materials/tests and e-format?

Does the book address different learning styles and strategies?

Does the activities and exercises introduce the main principles of CLT?

Does the e-book include self-assessment parts?

Can the activities be exploited fully and embrace various methodologies in ELT?

Is/are the type/s of syllabus design used in the book appropriate for learners?

Can the e-book easily be integrated into technology, thereby allowing for individual study outside the school?

Does the e-book fit curriculum/goals?

Are the objectives specified explicitly in the e-book?

Is the e-book design by taking into account the learners' socially and historically English-free status?

Functionalities

Are related elements of the content hyperlinked?

Are multimedia hypermedia part of the e-book?

Is the e-book equipped with an advance search tool which permits the reader to take a variety of search routes and use a range of search queries?

Can the reader customize elements of the e-book to his her liking/needs?

Journal on English as a Foreign Language, 8(1), 57-74

Copyright (C) 2018 by JEFL, p-ISSN 2088-1657; e-ISSN 2502-6615 
Are bookmarking and annotation tools available to the reader?

Device and Format

Does the e-book require an e-reader which is relatively cheap and available?

Is the e-book file format, i.e. will it be read by multiple brands of reading devices or a desktop computer?

Are reading rights restricted in any way, e.g. through a digital rights management (DRM) system?

Source: Demir and Ertas (2014)

The finding shows that $59 \%$ out of 66 criteria were met. Referring to the percentage conditions set out earlier (elaborated in the method section), this ebook was categorized into the third category: the e-book was not suitable to be used in the teaching and learning process. However, it is possible for English teachers to make improvements to the e-book by adapting the materials.

\section{English E-book 'Think Globally Act Locally' for the Ninth Graders Represents the Criteria of a Good Quality E-book}

The second research objective intended to figure out the extent to which the 2013 curriculum English electronic book 'Think Globally Act Locally' for the ninth graders meets the criteria of a good quality e-book.

\section{Subjects and Contents}

The findings show that the contents of the e-book did not serve as a window into learning about the target language culture (American, British, etc.). The e-book only includes literally three activities which exposed other cultures. The first one was a song entitle 'Que Sera Sera', the second was a folktale from Vietnam entitled 'The Golden Star-Fruit Tree', and the last one was a song entitled 93 million miles by Jazon Mraz. The contents in the e-book mostly included general topics so that all of the contents were considered culturally appropriate. The topics and texts were free from discrimination attributes (such as gender bias, racism, and stereotype) and sensitive materials (such as religions and politics).

\section{Sub-skills and Skills}

In exposing reading skills, the e-book did not quite provide adequate number of reading texts. Most of reading texts provided were in the form of conversation dialogues rather than in the form of long texts which introduce English text types (descriptive, narrative or recount text). It went the same with the exposure of writing skills. The actual writing did not exist in this e-book and the exposure of writing skills in this e-book was not adequate. There were only 
two genres of texts presented across the book; a procedure text and a narrative text. However, there was no instruction for students to write their own text. Instead, to compose a text, students were expected to fill in the blanks or rearrange sentences. The exercises related to writing were the ones such as writing to answer some questions, filling blank texts and composing a journal related to what have been discusses in a unit of the e-book.

Out of four language skills, listening and speaking were exposed the most in the e-book. The e-book offers a lot of listening activities in each unit. Most of the activities were about listening to the teacher while she/he reads a text or a conversation to students. The listening materials were accompanied by background information, questions and activities to help comprehension. The tasks were appropriate for learners to listen to as it revolved around learners' context, but the tasks were not authentic because they were not recorded and it was the teacher who expected to give the listening material instead of the target language speakers.

In addition, this e-book presented speaking tasks in each of the unit of the e-book. The tasks revolved around giving a presentation, doing a role play and repetition, and acting out a conversation in the book in pairs or groups. In addition, this e-book included speech situations relevant to students' background so they helped to initiate meaningful communication.

The vocabulary learning did not seem to become a priority in this ebook. There were only a few units which provided vocabulary loads. In unit ten, for example, vocabulary load was presented by integrating it with a filling gap task. A story was presented with some words taken out of it and they were spread in columns. Students were expected to learn the vocabulary and fill the gaps of the story afterwards. The vocabulary items learned unfortunately were not recycled in the following units in the effort to strengthen students' vocabulary knowledge.

Grammar learning was offered very well in this e-book. This e-book presented grammar learning by putting them in contexts instead of in complex charts and tables. One of the examples was strengthening students' knowledge on how to give suggestions of to do or not to do something. The e-book presented the grammar learning through a range of simple conversations by using pictures which will catch students' attention. Although grammar was presented in tables such as the learning of the changing of verbs in English, this e-book presented it in simple and colorful tables. However, grammar learning which were discussed in previous unit was not practiced and reinforced in subsequent lessons.

Pronunciation is another sub-skill which is required to be provided in a coursebook. Yet the e-book covers sub-skills like note-taking, skimming, 
scanning, and the like, for example students are asked to do a note-taking by writing what they have learned in the entire unit. Skimming and scanning were also integrated with the learning of other skill and sub-skills.

\section{Layout and Physical Make up}

For a starter, the publishing details were clearly mentioned in the beginning of the book to let the readers know about the information of the ebook authors, the publication date and the publisher of the e-book. The color of the layout of the e-book was clear and bright (no blurry layout). The pictures and texts were clear for users to see and read. Those qualities made the e-book look interesting and fun. The e-book presented the materials in pictures and tables with rich color made it to be visually appealing. The size and weight of the coursebook also become one of the criteria to be evaluated. Since this coursebook is in a digital form, the size and weight were considered to be convenient as the students do not have to physically carry the e-book in order to use it, as the e-book can be used in tablets, laptops and computers, and as the size of the e-book software is relatively small (12.2 MB). In addition, accessing the e-book is not difficult as having a downloaded e-book is enough to start the learning.

To ease learners, this e-book differentiated the cover in each unit by designing it in full pictures, writing the unit number and its theme in bold and bigger fonts and providing learning objectives which should be accomplish in each unit. However, the digital features of layout and physical make up such as the feature of navigation clues which makes particular elements of content accessible and color scheme to aid searching were not provided in this e-book, while Marczak (2013) expects those two things to characterize a good quality ebook. To access the e-book, the users literally have to scroll the e-book up and down to find the pages they wish to read.

\section{Practical Considerations}

Practical considerations consisted of several criteria. Wen Cheng, Chien Hung and Chung-Chieh (2011) suggest that a good coursebook is the one which is up-to-date or published within the past 10 years. This e-book, in fact, was published in 2015. Therefore, it is still considered as up-to-date.

The accessibility of the book is also a concern according to Litz (2005). In fact, this e-book was easily accessed through opening it from various e-book reader devices in computers, laptops or tables to start the access of the e-book. Next the cost to successfully get this e-book was considered relatively reasonable. The Ministry of Education and Culture has set up a website where people can download electronic coursebook without being charged. The users 
who attempt to download the e-book from the website only have to spare for the cost of internet access.

The principle of teaching methodology was also dealt and questioned in the criteria related to practical consideration. With the elaboration of good distribution of speaking tasks across the e-book, this e-book seemed to be a perfect fit for introducing the main principle of Communicative Language Teaching.

As the e-book was written and published by the Indonesian Ministry of Education and Culture based on the regulation defined in the curriculum about the core competence and basic competence, this e-book fulfilled curriculum goals. The e-book was such a reflection of 2013 curriculum. The 2013 Curriculum has what is so called as 'scientific approach'. It is an approach which regulates the steps taken in the teaching and learning practice in the classroom. It starts with asking students to observe, ask questions, gather resources or information, associate the information or the knowledge, and communicate. This e-book managed to organize its contents into these five stages of scientific approach. Therefore, it obviously specifies what is expected by the curriculum.

However, there were drawbacks in terms of the provision of supplementary materials such as tapes, visuals and the like to enrich learning resources. Razmjoo (2010) points out that those kinds of materials are needed to support learners with a good exposure to the language learning. This problem led to the failure of addressing different learning styles (visual, auditory, kinesthetic) of learners. The other flaw was that there was an absence of supporting online materials/tests and self-assessment parts in the e-book.

\section{Functionalities}

There were five criteria of a good quality e-book related to the functionalities. Marczak (2013) points out that a good quality e-book should have contents which are hyperlinked, have multimedia and provide an advance search tool. Unfortunately the e-book did not offer the criteria. There was no content which was hyperlinked. There was also no multiple media to support the learning in the e-book. The media was only the e-book itself. Advance search tools were also not equipped in the e-book (such as the tools to jump on relevant pages conveniently or to highlight important points). The users were expected to scroll up and down to do searching.

The e-book was really rigid in form which made it impossible for the users to customize the elements in the e-book to their own liking needs. There was also no possibility to do bookmarking and write annotation. Therefore, the 
function of the e-book was found to be quite restricted as the users were not possible to do anything with it other than to read it only.

\section{Device and Format}

There are three criteria in the form of questions under the major category of device and format according to Marczak (2013). The first and the second criteria were interrelated. They were related to the availability and affordability of an e-reader to open the e-book. Apparently, this e-book was possible to be accessed by using many kinds of pdf (portable document format) readers. Several e-readers are relatively reasonable as users only have to spare money on the cost of internet access to download the application. The e-book can also read by multiple brands of desktop computers which have been equipped with the installation of pdf reader.

The last criterion is related to DRM (Digital Rights Management) system. This system functions as a protection of any digital materials so that they are protected from being taken by people who do not have any right to take them. Yet, this e-book was not protected by using the aforementioned system as the fact that it is possible for people surf freely in the website (www.bse.kemdikbud.go.id/) to search for and download any e-book they wish to download.

\section{DISCUSSION}

As it is mentioned in the finding section, the e-book met $59 \%$ criteria of the good quality e-book. The e-book met the criteria of a good quality e-book to the extent that it is able to promote students communication skills. Mukundan et al. (2011) specify a good quality coursebook criteria are that the tasks should be developed to initiate meaningful communication. Some of speaking situations offered in this e-book were the ones dealing with the topic on congratulation on someone's success, giving suggestions and stating past activities. Those situations are closely related to students' daily activities. Kang (2005) believed that familiarity of topics is able to increase students' motivation and willingness to speak the new language because it has what so called as the sense of security. Therefore, the exposure to such speaking situations presented in the e-book is helpful to get them to be motivated and increase their willingness to speak English.

In addition, the e-book has successfully put students' daily life contexts into the e-book contents. Therefore, it is possible for students to learn English better as they can relate the learning to their real life activities. Contents related to congratulating someone's success and making suggestions are things that they often deal with in their daily lives. McKay (2003) believed that exposing 
students to contents related to their local contexts or the experiences they often deal with in their daily lives is more effective to initiate communication.

Despite the strengths, the e-book does not go without weaknesses. First, it has not yet successfully presented an equal exposure between foreign culture and the local culture learning. The e-book presented most of the contents in general topics which every culture shares and familiar with. The learning of a target language should also come with the learning of a target culture. Liu (2014) and Gómez Rodríguez (2015) acknowledged that culture and language learning cannot be separated as it influences students' understanding. Further Gómez Rodríguez (2015) mentioned that the selection of the target culture learning topics in EFL textbooks is expected to go beyond the surface. However, such topics which contain culture learning in language classrooms are expected to be well-selected to exclude inappropriate contents which are offensive, personal and impractical.

In addition, the e-book has not yet promoted authentic materials. Sample (2015) mentions that in the research he/she conducted, it showed that certain kinds of authentic materials contribute to students learning motivation. In the criteria checklist utilized to evaluate the e-book, the aspect of authenticity is asked in the category of skills and sub-skills. Belaid and Murray (2015) conducted a research on EFL teachers' attitude and perceptions toward authentic materials and found that authentic materials are expected to be exposed in the foreign language learning to familiarize students with how the target language is used or spoken in the target language speakers' real life. Gilmore (2007) acknowledged that there is a gap between authenticity and textbooks: textbooks present the language and tasks artificially rather than authentically.

\section{CONCLUSION}

Selecting a good quality e-book is not an easy task. A careful evaluation using lists of criteria should be carried out to discover the strengths and weaknesses of an e-book. This research investigated whether the 2013 curriculum e-book 'Think Globally Act Locally' for ninth graders was categorized into a good quality e-book and how the aforementioned e-book met the criteria of a good quality e-book.

By employing an e-book evaluation criteria checklist, the e-book was analyzed and the finding was obtained. The finding showed that the e-book met the criteria of a good EFL e-book to the extent that the e-book contents increase students' willingness to learn and to speak English by providing familiar topics. The e-book represented the contents by relating it to students' real-life situation, the e-book made a great exposure for students' speaking 
skills as there are a lot of speaking activities provided in the e-book (doing presentations, role play and acting out conversation), and the e-book had appealing layout or physical appearance.

However, some shortcomings were found in the e-book. First, the learning of the culture of the target language was not exposed very well. The second was that the e-book did not equally expose the four language skills and three sub-skills. The e-book did not accommodate audios to listen to in the effort to build students' listening skill, vocabulary loads, actual writing tasks, and pronunciation learning. Next, supplementary materials were not provided in the e-book. The other major flaw was the fact that the e-book was designed in a rigid digital form. It is not possible for students to customize, write notes and mark relevant section.

In conclusion, although the e-book only met 59\% criteria of a good quality e-book and fall under the third condition (explained in the data collection and analysis procedure section) which meant that the e-book was not suitable to be used in the teaching and learning process, teachers are able to do improvements to the e-book. It is possible for teachers to find and add the following materials: food labels, greeting cards, magazine, phone messages, or movies to familiarize students with the authenticity of English learning materials. Teachers can also use the topics of the e-book to integrate skills learning so that students experience the four language skills equally. With the right adjustments, a barely good EFL e-book can become a good EFL e-book.

Therefore, hopefully this research contributes novel ideas and encourages e-book writers, especially in Indonesia, to design and write a welldesigned e-books which accommodate features which are still missing from the e-book analyzed in this research. Further, as what is evaluated in this research is an electronic book, e-book writers and designers are expected to determine and accommodate digital features of e-books.

\section{REFERENCES}

Ansary, H., \& Babaii, E. (2002). Universal characteristics of EFL/ESL textbooks: A step towards systematic textbook evaluation. The Internet TESL Journal, $8(2), 1-9$.

Arba'ati, R. (2015). An analysis on English text book entitled Bahasa Inggris "When English Rings a Bell" for the eighth year student of junior high school based on the 2013 Curriculum. Publication Article. Surakarta: Muhammadiyah University of Surakarta. Retrieved from http://eprints.ums.ac.id

Belaid, A. M., \& Murray, L. (2015). Using authentic materials in the foreign language classrooms: Teachers' attitudes and perceptions in Libyan 
Universities. International Journal of Learning and Development, 5(3), 25-37 (http://dx.doi.org/10.5296/ijld.v5i3.8218).

Chou, P. T. (2010). Advantages and disadvantages of ESL course books. The Internet TESL Journal, 16(11).

Cohen, L, Manion, L., \& Morrison, K. (2007). Research methods in education (6 $6^{\text {th }}$ edition). United States of America: Routledge.

Creswell, J. W. (2011). Educational research. United States of America: Pearson.

Demir, Y., \& Ertas, A. (2014). A suggested eclectic checklist for ELT coursebook evaluation. The Reading Matrix, 14(2), 243-252.

Gilmore, A. (2007). Authentic materials and authenticity in foreign language learning. Language teaching, 40(2), 97-118.

Gomez Rodríguez, L. F. (2015). The cultural content in EFL textbooks and what teachers need to do about it. PROFILE Issues in Teachers' Professional Development, $17(2)$,

$167-187$ (http://dx.doi.org/10.15446/profile.v17n2.44272).

Harmer, J. (2007). The practice of English language teaching. Malaysia: Pearson Education Limited.

Kang, S. J. (2005). Dynamic emergence of situational willingness to communicate in a second language. System, 33(2), 277-292.

Litz, D. R. (2005). Textbook evaluation and ELT management: A South Korean case study. Asian EFL Journal, 48, 1-53.

Liu, Y. C. (2014). The use of target-language cultural contents in EFL teaching. International Journal of Humanities and Social Science, 4, 6(1), 243-247.

Marczak, M. (2013). Selecting an e-(text) book: Evaluation Criteria. Teaching English with Technology, 13(1), 29-41.

McKay, S. (2003). Teaching English as an international language: The Chilean context. ELT journal, 57(2), 139-148._Retrieved from https:/93fb33df-a62cb3a1a-s-sites.googlegroups.com

Mukundan, J., Hajimohammadi, R., \& Nimehcisalem, V. (2011). Developing an English language textbook evaluation checklist. Contemporary Issues In Education Research, 4(6), 21.

Nimasari, E. P. (2015). Evaluating an EFL textbook: to what extent does the 2013 curriculum-based textbook accomplish pedagogical aspects?. Prosiding ICTTEFKIP UNS. Vol. 1, No.1; January 2016.

Priajana, N., \& Baehaqi, L. (2012). The realization of e-books for teaching as reflected by EFL teachers of Islamic junior high school (MTs). Journal on English as a Foreign Language, 2(1), 51-57.

Razmjoo, S. A. (2010). Developing a textbook evaluation scheme for the expanding circle. Iranian Journal of Applied Language Studies, 2(1), 121-136. 
Sample, M. G. (2015). Authentic materials: a motivational tool for the EFL classrooms?. Education and Linguistics Research, 1(2), 100-119.

Sarem, S. N., Hamidi, H., \& Mahmoudie, R. (2013). A critical look at textbook evaluation: a case study of evaluating an ESP course-book: English for international tourism. International Research Journal of Applied and Basic Sciences. Vol 4(2), 372-380.

Sholihah, U. (2016). An analysis of English textbook for eleventh year students of senior high school on the basis of the 2013 curriculum. Magistra, 28(95).

Wen-Cheng, W., Chien-Hung, L., \& Chung-Chieh, L. (2011). Thinking of the textbook in the ESL/EFL classroom. English Language Teaching, 4(2), 91-96.

Zohrabi, M. (2011). Coursebook development and evaluation for English for general purpose course. English Language Teaching, 4(2), 213.

\section{Authors' Brief CV}

Sri Meiweni Basra is affiliated at Universitas Negeri Padang and now is a fulltime postgraduate student of English Education Program in Universitas Indonesia. She has presented two papers in international conferences. Her research interest includes in English Education, Textbook Evaluation, and Pragmatics Studies.

Pupung Purnawarman is a faculty member at the Department of English Education, FPBS, Universitas Pendidikan Indonesia. He was a recipient of Fulbright Scholarship and completed his masters and doctoral programs at Southern Illinois University and Virginia Polytechnic and State University (Virginia Tech) respectively. His research interest includes TEFL/TESL, Writing Instruction, Feedback, Instructional Design and Technology, and Lesson Study. He is also a reviewer in several journals, both national and international. 